Research Article

\title{
Inkjet-Printed Flexible MEMS Switches for Phased-Array Antennas
}

\author{
Mahmuda Akter Monne, ${ }^{1}$ Xing Lan, ${ }^{2}$ Chunbo Zhang, ${ }^{2}$ and Maggie Yihong Chen $\mathbb{D}^{1}$ \\ ${ }^{1}$ Ingram School of Engineering, Texas State University, San Marcos, TX 78666, USA \\ ${ }^{2}$ One Space Park, Northrop Grumman, Redondo Beach, CA 90278, USA \\ Correspondence should be addressed to Maggie Yihong Chen; maggie.chen@txstate.edu
}

Received 30 December 2017; Accepted 8 February 2018; Published 28 March 2018

Academic Editor: Herve Aubert

Copyright (C) 2018 Mahmuda Akter Monne et al. This is an open access article distributed under the Creative Commons Attribution License, which permits unrestricted use, distribution, and reproduction in any medium, provided the original work is properly cited.

\begin{abstract}
This paper presents a fully inkjet-printed flexible MEMS switch for phased-array antennas. The physical structure of the printed MEMS switch consists of an anchor with a clamp-clamp beam, a sacrificial layer, and bottom transmission lines. 5-mil Kapton ${ }^{\circledR}$ polyimide film is used as a flexible substrate material. Two different types of conductive ink PEDOT: PSS from Sigma Aldrich and silver nanoparticle ink from NovaCentrix are used for the fabrication of different printed layers. Layer-by-layer fabrication process and material evaluation are illustrated. Layer characterization is done with respect to critical thickness and resistance using 2D/3D material analysis. Fujifilm Dimatix Material Printer (DMP-2800) is used for fabrication, and KLA-Tencor (P-7) profiler is used for $2 \mathrm{D}$ and $3 \mathrm{D}$ analysis of each layer. The MEMS switch has a low actuation voltage of $1.2 \mathrm{~V}$, current capacity of $0.2195 \mathrm{~mA}$, a current on-off ratio of $2195: 1$, and an RF insertion loss of $5 \mathrm{~dB}$ up to $13.5 \mathrm{GHz}$. Printed MEMS switch technology is a promising candidate for flexible and reconfigurable phased-array antennas and other radio frequency (RF) and microwave frequency applications.
\end{abstract}

\section{Introduction}

Digitals beamforming phased-array antennas (PAAs) with distributed control and processing electronics offer numerous advantages for radio frequency (RF) communications, such as electronically controllable beamforming and steering, high average transmitted power and efficiency, flexible subarraying to provide multiple communication links simultaneously, reconfigurable high-gain patterns, and increased reliability through reconfiguring redundant array elements. Low-cost, high-gain, lightweight, and conformal active PAA on flexible substrates is of particular interest in space communication networks. However, the major deterrent to developing such systems is the difficulty in integrating antenna and electronic circuits on the flexible surface, especially the switch-controlled phase shifters and amplifiers. Previously, a prototype of active PAA is designed using carbon nanotubes (CNT) as the active material in the digital switching device [1]. However, the printed flexible CNT transistor switch is limited to $5 \mathrm{GHz}$ [2]. Graphene transistor potentially has higher working frequency. However, the current on-off ratio is limited to 38 due to the intrinsic zero-bandgap property $[3,4]$. A MEMS switch theoretically has unlimited bandwidth and on-off ratio due to the mechanical property. However, there is no report about highperformance fully printed flexible MEMS switch.

The attractiveness of printing technology is due to its greatly simplified fabrication process. In this process, it is possible to achieve multilayered microstructures and thinfilm devices in a simple and cost-effective way [5-7]. The most widely used printing techniques are inkjet, aerosol jet, screen printing [8], flexographic printing, and gravure printing [8]. The sheet-based inkjet printing technique has been gaining attention because of its unique features, such as simplicity of fabrication, compatibility with different substrates, feasibility of noncontact, low-temperature processing, and low cost. Aerosol jet printing offers one of the best printing resolutions with good flexibility, but the 
TABLE 1: Commercially available polymers for printed electronics.

\begin{tabular}{lcc}
\hline Name & Specifications & Properties/current limits \\
\hline $\begin{array}{l}\text { Riston }{ }^{\circledR} \text { (DuPont) } \\
\text { Kapton (DuPont) }\end{array}$ & Dry film & $\begin{array}{c}\text { A "general purpose" dry film for acid and alkaline etch up to } 15 \mu \mathrm{m} \\
\text { A "general purpose" dry film for printing with all types of nanoparticle ink } \\
\text { (Ag, Au, and CNT) }\end{array}$ \\
$\begin{array}{l}\text { NovaCentrix Novela }{ }^{\circledR} \\
\text { (NOVELA Advance Microsystem) }\end{array}$ & One-sided dry film & $\begin{array}{c}\text { Substrate thickness: } 10-25 \mu \mathrm{m} \\
\text { Minimum track width and spacing: } 10 \mu \mathrm{m}\end{array}$ \\
\end{tabular}

tool and its setup are more expensive than the comparatively low-cost inkjet printing.

Furthermore, inkjet printers can be divided into two basic process groups: continuous and drop-on-demand $[9,10]$. In continuous inkjet printers, the ink is first pumped through a nozzle forming a liquid jet. Next, the formed liquid jet is deflected by electrostatic plates to the paper or to a reservoir for recirculation. Today, most inkjet printers are based on a drop formation process, which is called dropon-demand (DOD) [9, 11]. The drop-on-demand method provides smaller drops and higher placement accuracy compared to the continuous inkjet printers. In this study, drop-on-demand inkjet printing is used [12]. The pulse that creates the ink drop can be generated either thermally or piezoelectrically. In our work, a Fujifilm Dimatix piezoelectric type inkjet printer is used.

Currently, a large variety of MEMS devices such as sensors, actuators, and switches are available [13-15]. These devices, however, are mostly developed and fabricated by cleanroom micromachining technology, which is complicated in its processing steps and expensive to develop. The subtractive nature of the micromachining also incurs material waste and is not environmentally friendly [16, 17]. So far, there are very few research articles found from literature on printed MEMS devices. MEM relay is one of them, which was published in February 2016 [18]. However, the fabrication process of the mentioned article was not fully based on printing technology. Instead, the fabrication process was a combination of inkjet printing technique and another thin film deposition (spin coating) and etching technique. Only the electrodes of the MEM relay were fabricated using inkjet printing technique, while other layers like gate insulator and sacrificial layers were fabricated by spin coating and chemical etching (preparation of via holes). In the same article, they reported several measurements with respect to pull-in voltage $(7.2 \mathrm{~V})$, turn on delay $(8 \mu \mathrm{s})$, on-off ratio $\left(10^{8}\right)$, and on state resistance $(3.7 \Omega)$. It is to be noted that from the literature review, other than this article, there are no fully printed MEMS switch reported.

In this work, we explore the design, fabrication, and characterization of the fully 3D inkjet-printed flexible MEMS switches where all the layers like electrodes, sacrificial layer, cantilever, and anchor were fabricated using inkjet printing technology. The MEMS switch is a key component of phase shifter and can be printed together with antenna elements to develop a fully printed active phased-array antenna system.
TABle 2: Typical properties of PEDOT [22].

\begin{tabular}{lc}
\hline Properties & Parameters \\
\hline Visual appearance & Dark blue liquid \\
Solid content & $0.8 \mathrm{wt} \%$ \\
Viscosity & $7-12 \mathrm{cP}$ \\
Surface tension & $31-34 \mathrm{mN} / \mathrm{m}$ \\
$\mathrm{pH}$ & $1.5-3.0$ \\
Surface resistance & $110 \Omega / \mathrm{sq}$. \\
Shelf life & 6 months \\
\hline
\end{tabular}

\section{Material Evaluation for Inkjet Printing of MEMS Switches}

Polymeric material is used in most flexible electronics and/or organic electronic applications. A polymeric solid is made of many repeating molecules called monomers. Polymers can exhibit various mechanical, electrical, and optical properties depending on the synthesis conditions and chemical properties. The electrical conductivity of insulating polymers is about $10^{-18} \mathrm{~S} / \mathrm{m}$ whereas that of doped trans-polyacetylene is $10^{7} \mathrm{~S} / \mathrm{m}$ [19]. Some polymers such as poly(cis-1,4-isoprene) and poly(chloromethylstyrene) are sensitive to highenergy radiation. If the polymer is exposed to ultraviolet light, the chemical properties, such as solubility, of the polymer in the exposed area change. Photolithography is a very well-known process in electronics that uses this principle. To understand the electronic properties of polymers, it can be considered that each monomer has its electron orbitals in a certain electronic state [19]. Table 1 shows some commercially available substrate polymers. A Kapton film (HN type) of thickness $125 \mu \mathrm{m}$ from DuPont was used as a substrate in this research. As per manufacturer specifications, Kapton film can be used at temperatures as low as $-269^{\circ} \mathrm{C}$ and as high as $400^{\circ} \mathrm{C}$ [20]. Kapton film is chosen as the substrate for this work due to its flexibility, high temperature operability $\left(400^{\circ} \mathrm{C}\right)$, and low elastic coefficient. As acid etching is one of the important steps during device fabrication, it is also important to choose a substrate whose performance is not degraded by acid.

To print either in a large scale, such as a functional circuit, or in a very small scale, such as a nanometer-sized device, will require careful thought and engineering for the printing parameter settings. Unfortunately, these two opposing dimension extremes do appear in a single MEMS device that we designed, as both large-scale transmission lines and small-scale device details are present. To prevent 


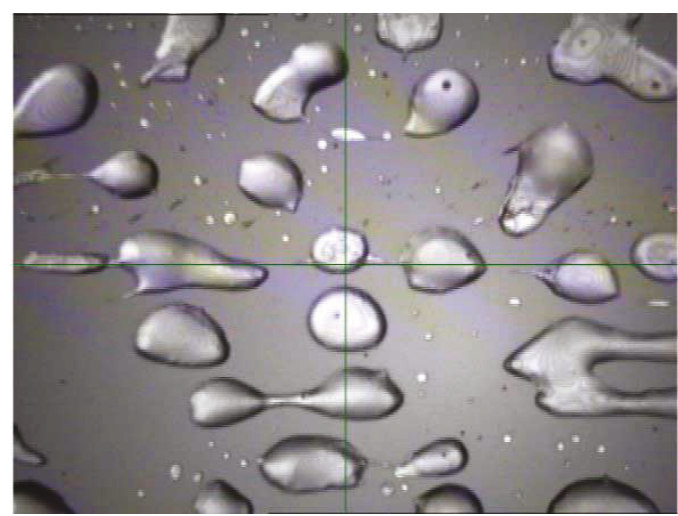

(a)

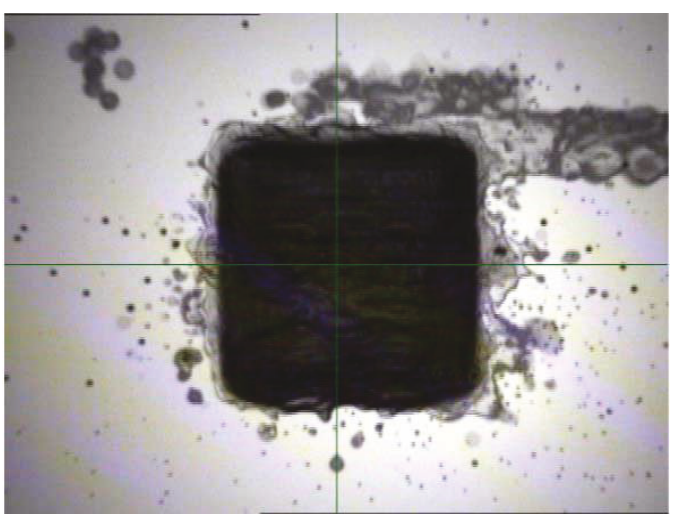

(b)

FIGURE 1: Surface treatment effect on PEDOT printing: (a) without surface treatment and (b) with surface treatment $(5 \mathrm{~mm} \times 5 \mathrm{~mm}$ pattern).

TABLE 3: Set parameters during the printing of each type of material.

\begin{tabular}{lcccccc}
\hline Material ink & $\begin{array}{c}\text { Nozzle } \\
\text { voltage }(\mathrm{V})\end{array}$ & $\begin{array}{c}\text { Drop } \\
\text { spacing }(\mu \mathrm{m})\end{array}$ & $\begin{array}{c}\text { Angle between print head } \\
\text { and cartridge }(\text { degree })\end{array}$ & $\begin{array}{c}\text { Meniscus } \\
\text { point }\end{array}$ & $\begin{array}{c}\text { Platen } \\
\text { temperature }\left({ }^{\circ} \mathrm{C}\right)\end{array}$ & $\begin{array}{c}\text { Cartridge } \\
\text { temperature }\left({ }^{\circ} \mathrm{C}\right)\end{array}$ \\
\hline PEDOT & 30 & 25 & 5.6 & 4.0 & 38 & 26 \\
Ag & 26 & 35 & 8.2 & 4.5 & 48 & 28 \\
\hline
\end{tabular}

the deviation in operation of the nozzles of Fujifilm Dimatix, testing of each of the 16 nozzles is necessary before any printing operation. It was found from a review of the literature and our experimental work, for small pattern or feature printing, that the usage of a single nozzle provides more consistent results than using multiple nozzles.

Two types of conductive inks were used throughout the research: PEDOT (poly(3,4-ethylenedioxythiophene)poly (styrene sulfonate)) high-conductivity grade from Sigma-Aldrich was used for transmission line and clampclamp beam fabrication. Metalon silver ink (JSB-40G) from NovaCentrix was used for the sacrificial layer. The viscosity of the silver ink is about $8-10 \mathrm{cP}$ with surface tension 28-32 dyne/cm [21]. On the other hand, PEDOT is a water-based ink. Deposition of PEDOT on top of Kapton is difficult as it is a water-based ink and the surface of the substrate is hydrophobic. Therefore, the surface of the Kapton substrate needs special treatment and a modified printing environment to promote adhesion for printing with PEDOT ink.

It is also observed that, by setting a minimum distance between the cartridge nozzles and substrate and a lower waveform triggering voltage of around $20-26 \mathrm{~V}$, it was possible to achieve very small printed structure sizes during ink deposition. Furthermore, it was seen that using only one nozzle at a time during printing resulted in quality outputs.

2.1. PEDOT Ink Evaluation. PEDOT is used to fabricate two of the most important portions of the printed MEMS switch, namely, transmission lines and clamp-clamp beam. The reason behind choosing PEDOT for these two parts is its acid-resistant property. It is a polymer-type ink not reactive to acid which is required for the MEMS fabrication. Also,

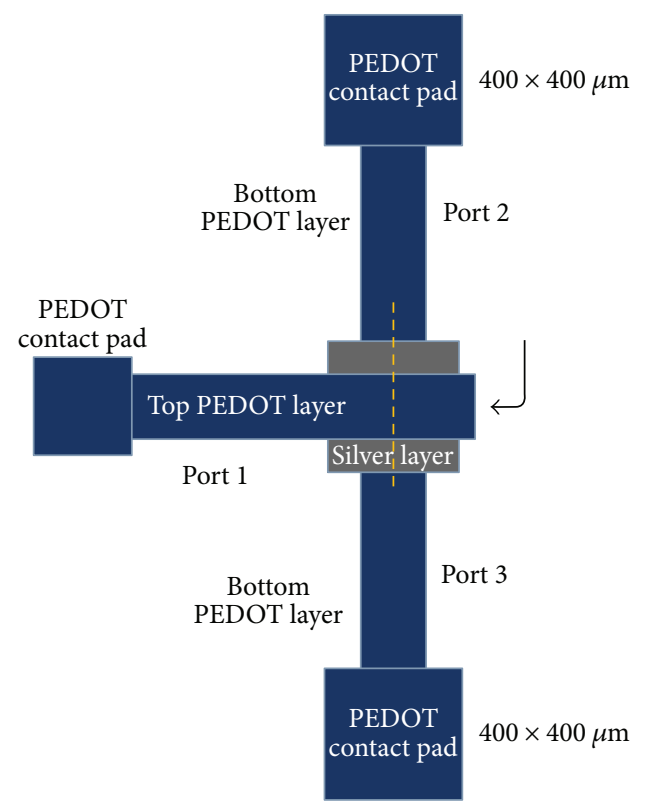

(a)

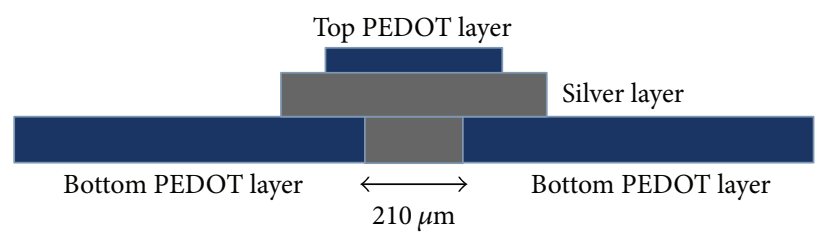

(b)

FIgURE 2: Schematic (a) top view and (b) cross-sectional view of the designed MEMS switch along the dashed line plane. 


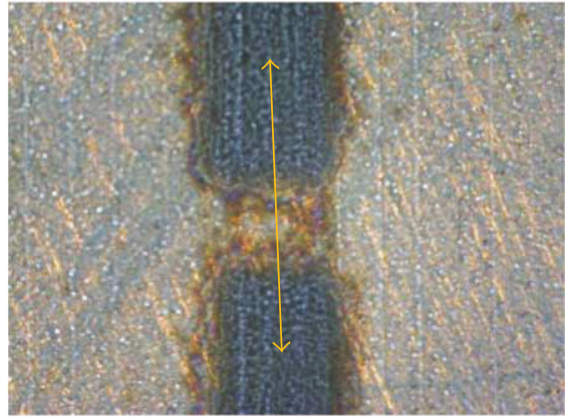

(a)

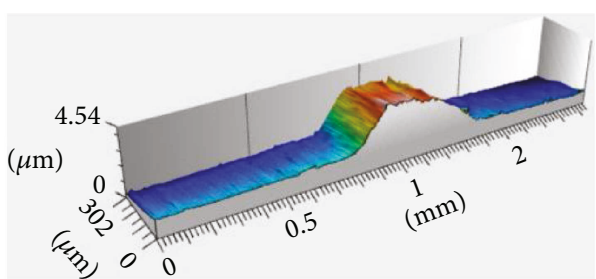

(b)

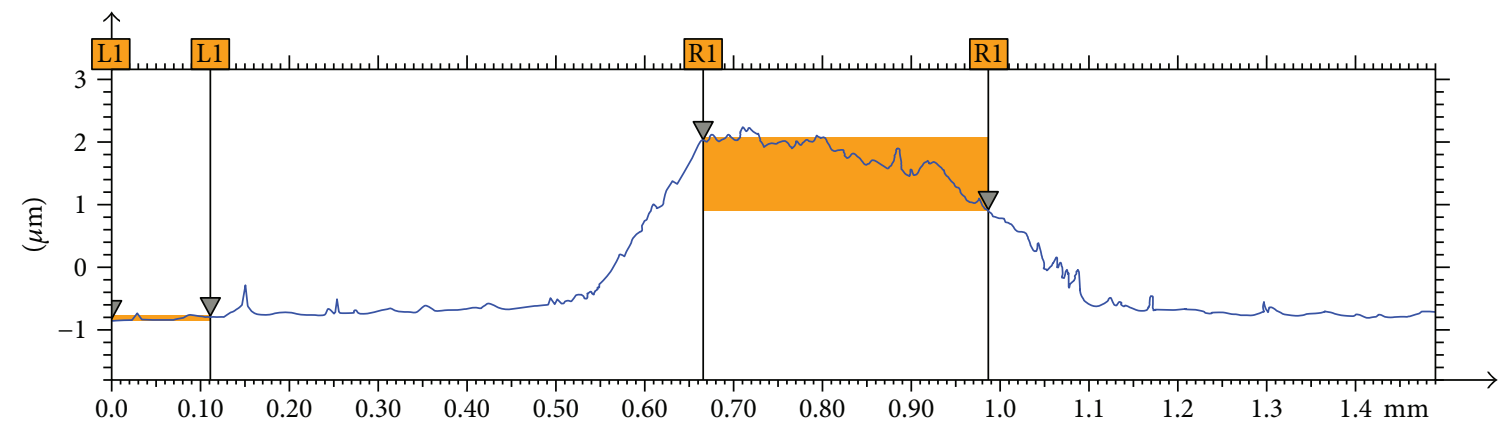

\begin{tabular}{|l|l|l|l|}
\hline Parameters & \multicolumn{1}{l|}{1} & \multicolumn{1}{l|}{ Unit } \\
\hline StpHt & 2.59 & $\mu \mathrm{m}$ & \\
\hline
\end{tabular}

(c)

FIgURE 3: (a) First printed PEDOT layer on Kapton substrate. (b) APEX 3D thickness analysis. (c) Thickness measurement by KLA-Tencor.

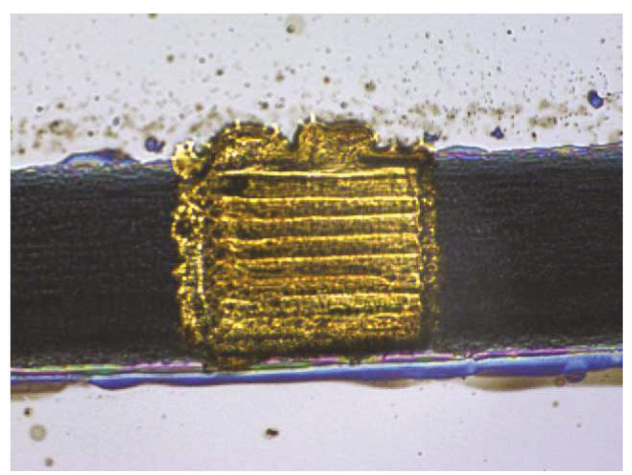

(a)

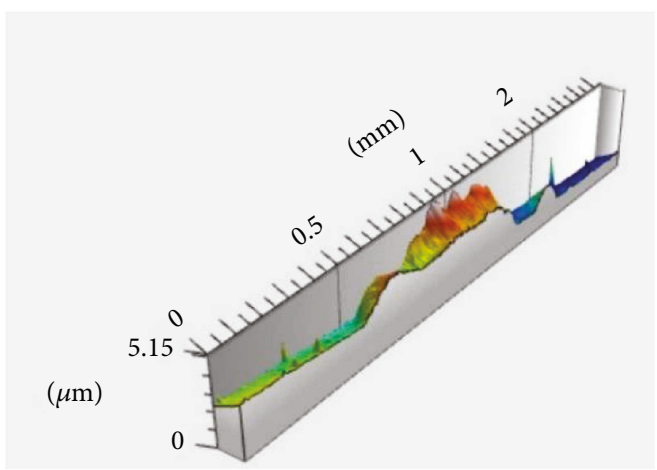

(b)

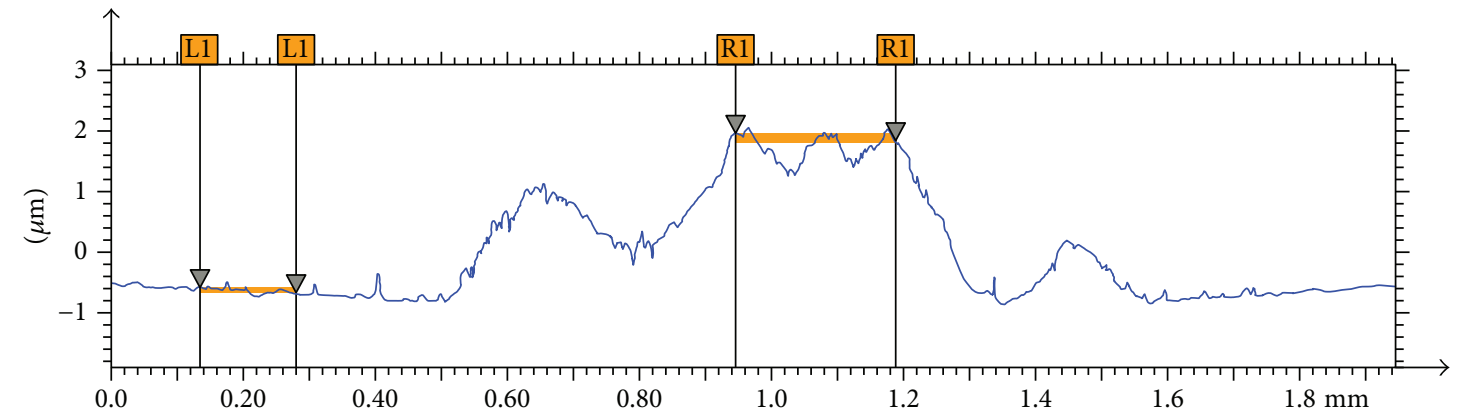

\begin{tabular}{|l|l|l|l|}
\hline Parameters & \multicolumn{1}{l|}{1} & Unit \\
\hline StpHt & 2.35 & $\mu \mathrm{m}$ & \\
\hline
\end{tabular}

(c)

Figure 4: (a) Printed sacrificial layer on top of PEDOT. (b) APEX 3D analysis. (c) 2D analysis of the layer for thickness measurement. 


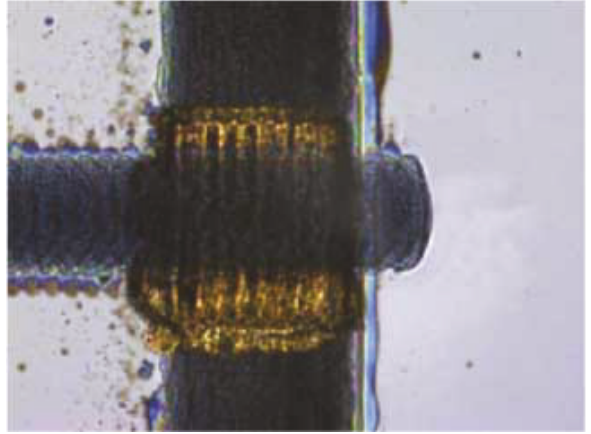

(a)

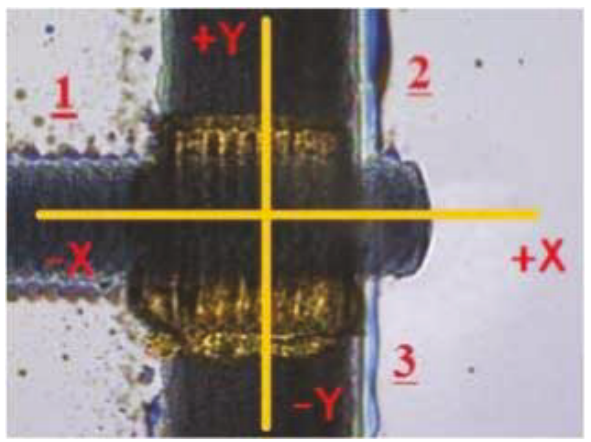

(b)

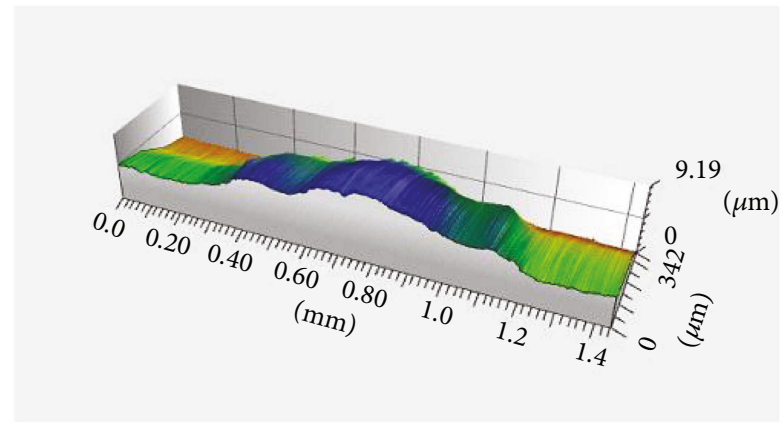

(c)

Figure 5: (a) Complete three-layer device. (b) Three terminals labeled for further data measurement. (c) 3D view of the printed layers to check uniformity (scanning was taken along the direction of $-\mathrm{Y}$ to $+\mathrm{Y}$ ).

TABle 4: Measured resistance before etching.

\begin{tabular}{lc}
\hline Terminal points & Resistances $(\Omega)$ \\
\hline $1-2$ & $387 \sim 430$ \\
$1-3$ & $300 \sim 330$ \\
$2-3$ & $700 \sim 1000$ \\
\hline
\end{tabular}

PEDOT has relatively low viscosity which makes it suitable for inkjet printers. Table 2 shows the typical properties of PEDOT [22].

PEDOT is stored between $4^{\circ} \mathrm{C}$ and $25^{\circ} \mathrm{C}$ in a vacuum freezer. As mentioned earlier, to achieve good printing results with PEDOT, surface treatment of the substrate is needed. Figure 1 shows the printing of PEDOT without

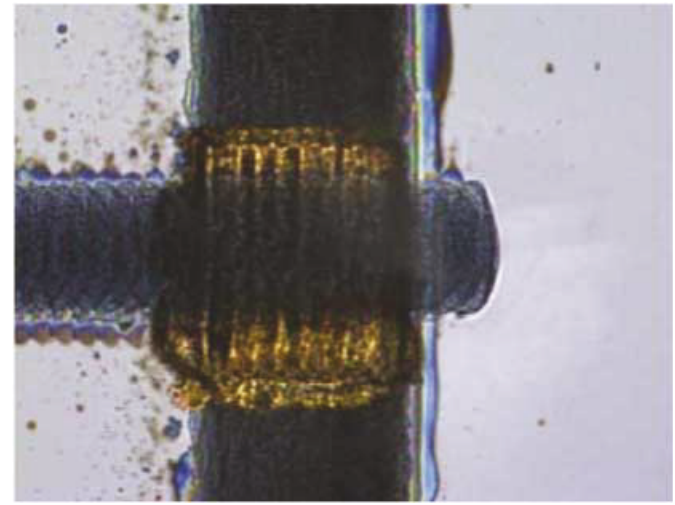

(a)

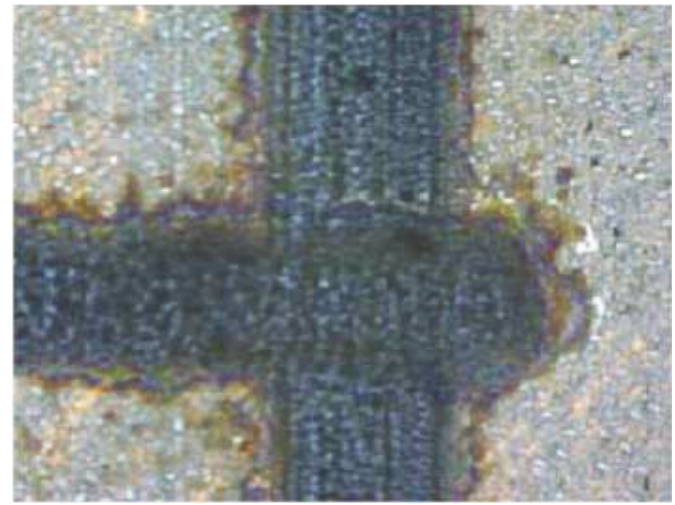

(b)

Figure 6: (a) Complete device before etching. (b) Complete device after etching.

TABLE 5: Measured resistance after membrane release.

\begin{tabular}{lc}
\hline Terminal points & Resistances $(\mathrm{M} \Omega)$ \\
\hline $1-2$ & $0.2 \sim 0.3$ \\
$1-3$ & $0.15 \sim 0.2$ \\
$2-3$ & $0.45 \sim 0.5$ \\
\hline
\end{tabular}

and with surface treatment. A significantly better pattern printing is achieved after surface treatment by oxygen plasma cleaning at 100 watts for 5 minutes. It should be noted that oxygen plasma treatment increased the adhesion to the substrate surface. For PEDOT printing, the firing voltage setting for the print head is between 20 and $25 \mathrm{~V}$, with firing frequency at $5 \mathrm{kHz}$ and cartridge temperature of $24^{\circ} \mathrm{C}$. The platen temperature was held at $38^{\circ} \mathrm{C}$ during printing. Table 3 shows the set parameters of the Fujifilm Dimatix Material Printer during deposition.

2.2. Silver Ink Evaluation. In the prototype MEMS device fabrication, silver layer is used as a sacrificial layer which will be removed after the device fabrication. Metalon silver ink is highly conductive at standard curing temperatures $\left(120^{\circ} \mathrm{C}\right.$ for $10 \mathrm{~min}$. and $220^{\circ} \mathrm{C}$ for $30 \mathrm{~min}$.). After a standard curing process, a $1 \mathrm{~cm}$ by $1 \mathrm{~cm}$ silver patch gives $1.22 \Omega$ 


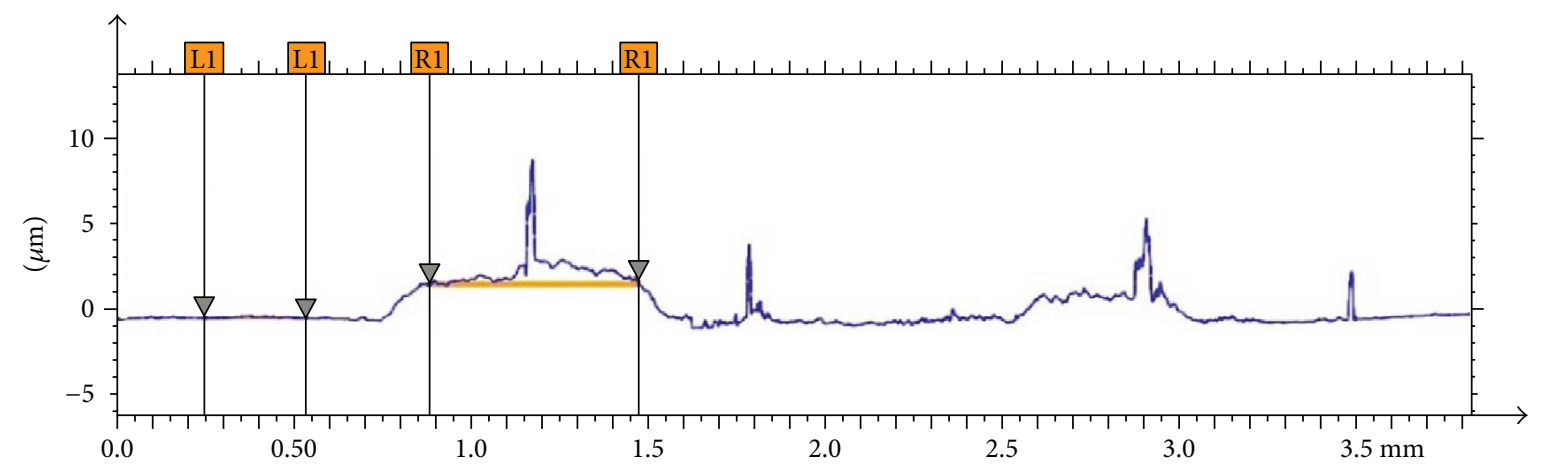

\begin{tabular}{|l|c|c|c|}
\hline Parameters & \multicolumn{1}{c|}{1} & \multicolumn{1}{c|}{ Unit } & \\
\hline StpHt & 2.77 & $\mu \mathrm{m}$ & \\
\hline
\end{tabular}

(a)

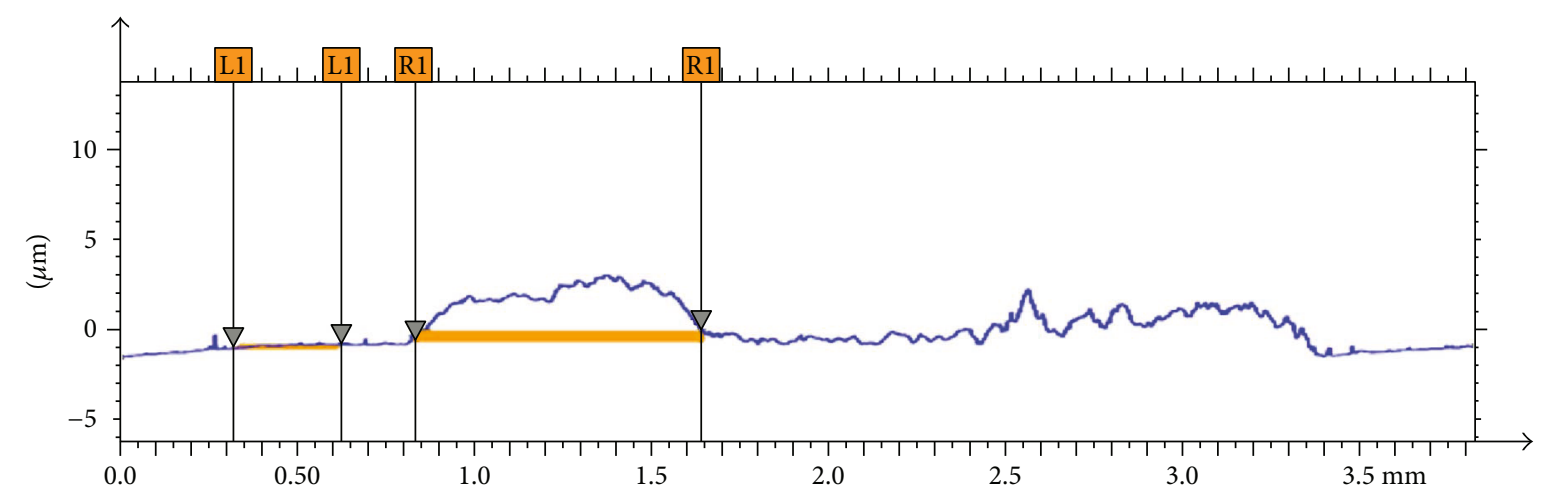

\begin{tabular}{|l|c|c|l|}
\hline Parameters & \multicolumn{1}{c|}{1} & Unit \\
\hline StpHt & 2.77 & $\mu \mathrm{m}$ & \\
\hline
\end{tabular}

(b)

Figure 7: Thickness comparison: (a) before etching and (b) after etching.

resistance with a thickness of $0.75 \mu \mathrm{m}$ for a printing parameter of 30 to $35 \mu \mathrm{m}$ drop spacing.

\section{Design and Fabrication of MEMS Switch}

Figure 2 shows the schematic top view and cross-sectional view of the designed MEMS switch. According to the design, the two transmission lines have a separation of $210 \mu \mathrm{m}$, and the length and width of clamp-clamp beam are $1400 \mu \mathrm{m}$ and $260 \mu \mathrm{m}$, respectively. Three contact points are also printed at the three terminals of the switch. Two ends of the transmission line contacts have dimensions of $400 \mu \mathrm{m}$ by $400 \mu \mathrm{m}$ and the beam end contact has a dimension of $290 \mu \mathrm{m}$ by $290 \mu \mathrm{m}$. The dimensions of clamp-clamp contact point are less than that of the other two to achieve a minimum weight.

3.1. Analysis of the Bottom Transmission Line Layer. Figure 3(a) shows the image of the first printed layer of the device, which is the transmission line consisting of deposited PEDOT polymer ink. The image was taken by KLA-Tencor process camera. This transmission line has an average thickness of $2.59 \mu \mathrm{m}$. Figure $3(\mathrm{~b})$ is the uniformity analysis in $3 \mathrm{D}$, and Figure 3(c) shows the $2 \mathrm{D}$ thickness measurement. This step needs a total of 20 layers of printed PEDOT to achieve the designed critical thickness.

From Figure 3(a), it appears that the two transmission lines are shorted by a slight amount of contact. The reason for this is the spreading of ink during printing. But the amount of PEDOT is quite small, and the amount of spreading is not significant enough to short the path. The measured resistances between the two transmission lines were found to be infinite which proved that the two transmission lines were not shorted. Additionally, the end-to-end resistance of a single PEDOT transmission line is measured to be between 1.1 and $2.0 \mathrm{k} \Omega$.

3.2. Analysis of the Silver Sacrificial Layer. Figure 4(a) shows the second printed layer which is the Ag sacrificial layer of the device. The average thickness of this layer is about $2.35 \mu \mathrm{m}$. Figure 4(b) shows the uniformity of deposited Ag metallic ink by APEX 3D analysis, and Figure 4(c) shows the $2 \mathrm{D}$ thickness measurement. The Ag sacrificial layer is needed with a total of three printed layers to achieve the required critical thickness.

3.3. Membrane Releasing of Printed MEMS Switch. Figure 5(a) shows a complete three-layer printed device. 


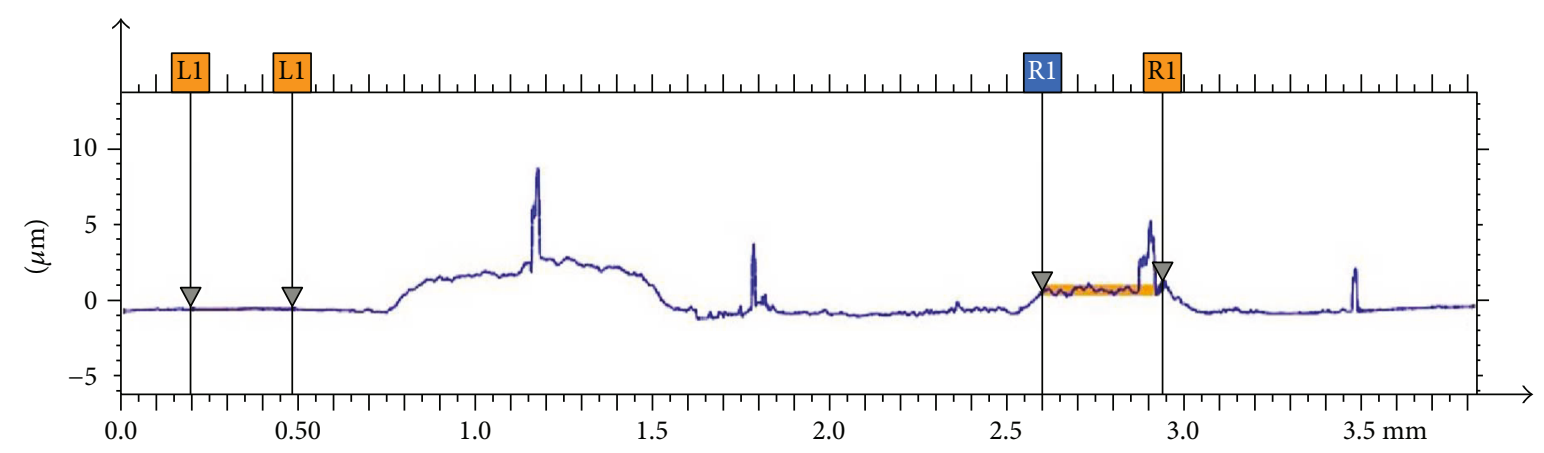

\begin{tabular}{|l|c|c|l|}
\hline Parameters & \multicolumn{1}{|c|}{1} & \multicolumn{1}{l|}{ Unit } \\
\hline StpHt & 1.58 & $\mu \mathrm{m}$ & \\
\hline
\end{tabular}

(a)

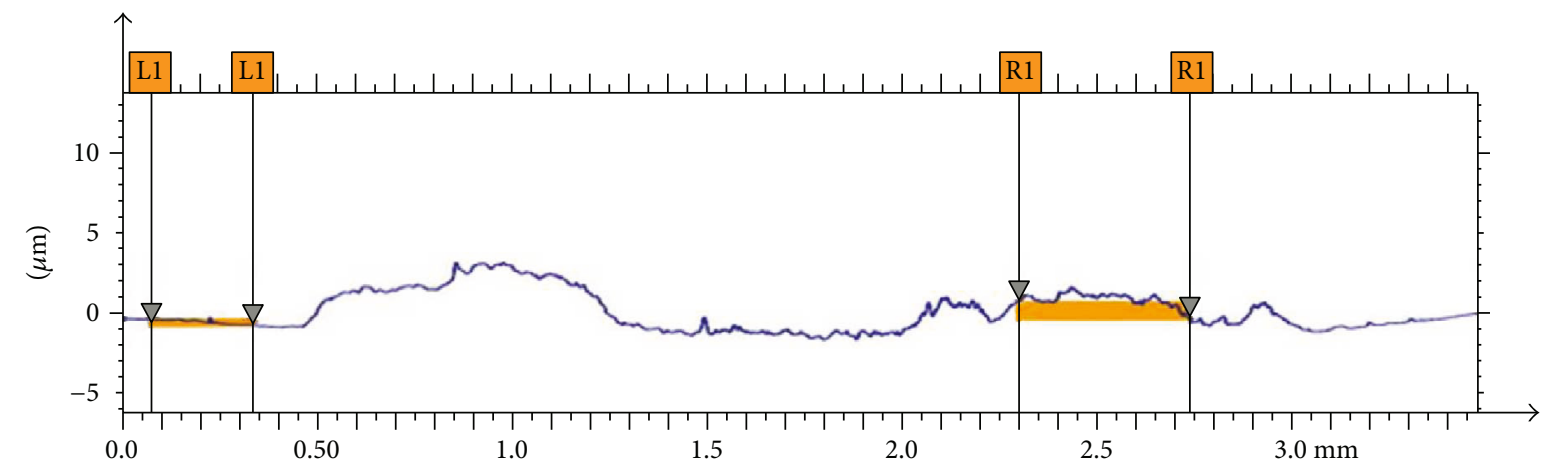

\begin{tabular}{|l|c|c|l|}
\hline Parameters & \multicolumn{1}{c|}{1} & \multicolumn{2}{c|}{ Unit } \\
\hline StpHt & 1.42 & $\mu \mathrm{m}$ & \\
\hline
\end{tabular}

(b)

FIGURE 8: Thickness comparison in anchor region (a) before etching and (b) after etching.

Figure 5(b) shows the pointed terminals as 1, 2, and 3. In this image, the clamp-clamp beam, transmission line 1 , and transmission line 2 terminals are labeled as 1, 2, and 3, respectively. Figure 5(c) shows the uniformity of printed layers by APEX 3D analysis. The purpose of thickness analysis is to maintain the critical thickness of each layer of the device. Next, the thickness of the sacrificial layer is used to calculate the approximate pull-down/actuation voltage. KLA-Tencor scanning has been taken in either the $-\mathrm{Y}$ to $+\mathrm{Y}$ direction (Figure 4 ) or the $-\mathrm{X}$ to $+\mathrm{X}$ direction (Figure 5).

Table 4 is the measured resistance between any two of the three terminals of the fabricated switch. It should be noted that Ag is a highly conductive material ink. Before the removal of sacrificial Ag layer, it is shorting the three terminals of the switch. From Table 4, the smaller resistances indicate the shorted path among these three terminals due to the Ag sacrificial layer.

An acid solution is used for etching the Ag sacrificial layer and releasing the membrane. Figures 6(a) and 6(b) show the complete MEMS switch before and after etching. It took about 15 minutes to completely release the

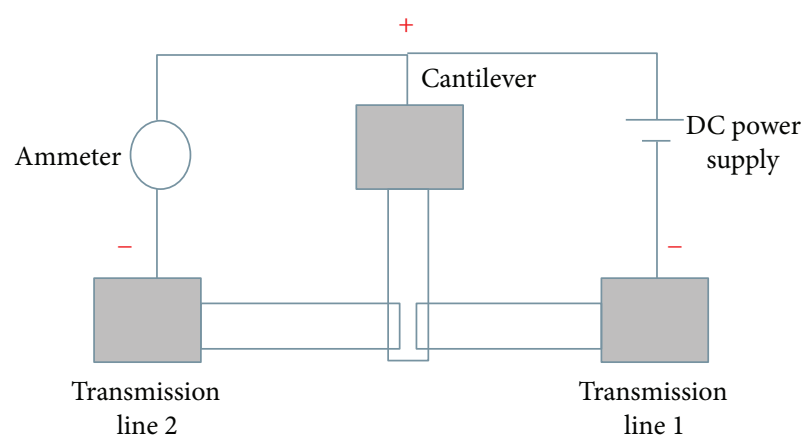

Figure 9: Circuit configuration for DC testing.

membrane. It is also evident from Figure 6(b) that the Ag sacrificial layer is completely etched off. End-to-end terminal resistance is measured, which will indicate whether the membrane is completely released or not.

Table 5 shows the resistances between any two of the three terminals of the MEMS switch after etching the Ag sacrificial layer. According to the original design, after the removal of the sacrificial layer, there should not be any 


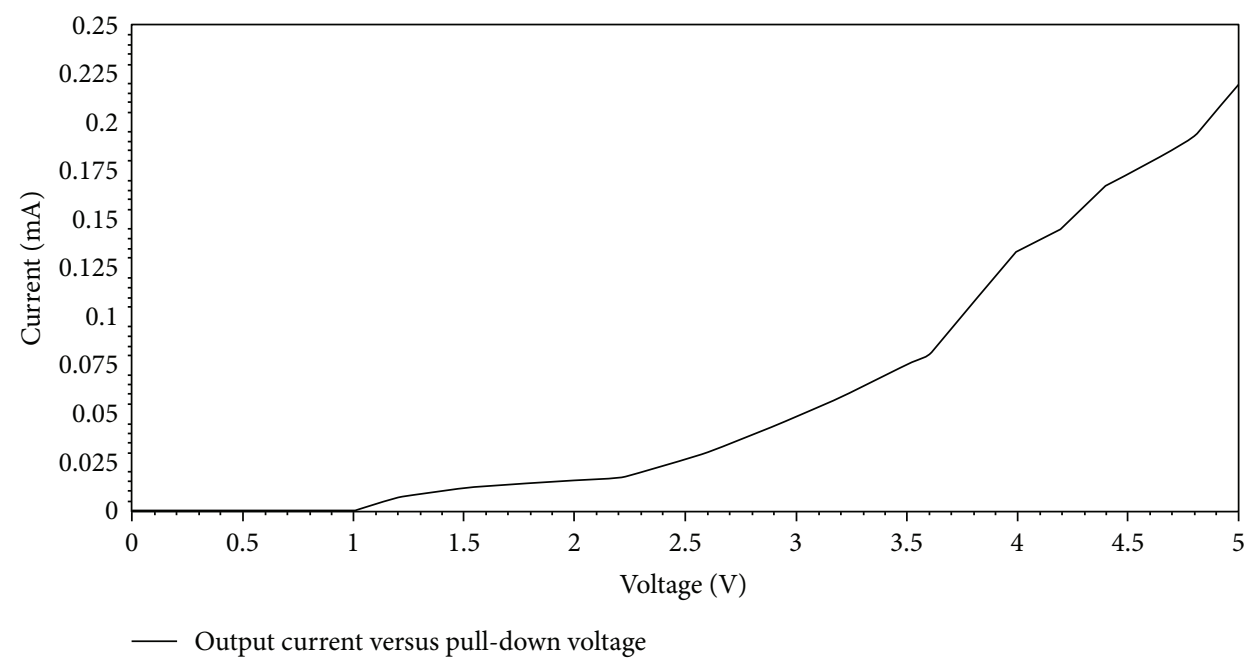

FiguRE 10: Input voltage versus output current.

physical contact among three terminals. So, theoretically, the resistances between the terminals should be very high after removing the sacrificial layer. High resistance values between any two terminals in Table 5 prove that the membrane has been released successfully. Another way to prove a successful membrane release is to compare the thickness measurement before and after etching.

3.4. Thickness Comparison before and after Membrane Release. Figure 7 shows the thickness comparison before and after etching. Scanning was taken along the $-\mathrm{X}$ to $+\mathrm{X}$ direction (Figure 7(b)). It is seen in Figure 7(a) that the thickness of the sacrificial layer region was $2.77 \mu \mathrm{m}$ before etching, and Figure 7(b) shows that the thickness measurement of the same region after etching is $2.76 \mu \mathrm{m}$. The measured profile of the post release air gap in Figure 5 is further proof that the release has been done successfully. Although the clampclamp beam dropped down a little bit about $0.01 \mu \mathrm{m}$, there is still quite a large air gap between the beam and transmission lines as the measured resistance is very high in between any two terminals.

Additionally, Figure 8 shows the comparison of 2D thicknesses in the anchor region. These two thicknesses are also almost the same for before and after etching, which proves that the clamp-clamp was still hanging with some air gap in between the clamp-clamp beam and transmission lines.

\section{DC and RF Characterization of the Printed MEMS Switch}

Two different connection schemes are used to analyze the DC performance analysis of the switch. Figure 9 shows the schematic diagram of connection. The input voltage is applied between the clamp-clamp beam and transmission line 1, and output signal is taken using an ammeter in between the clamp-clamp beam and transmission line 2 . The application for this MEMS switch requires that the input signal is applied on one side of the transmission line and the output is collected from the other side when the switch is turned on. The input signal was applied by an external power supply (model: GPS-3303), and the output was measured by the ammeter option of a multimeter (model: HP 34401 A).

By using the power supply, applied voltage is increased gradually from $0 \mathrm{~V}$ to $5 \mathrm{~V}$ which is incremented by $0.2 \mathrm{~V}$. It is seen that there were very small current $(0.0001 \mathrm{~mA})$ or no current output till $1.0 \mathrm{~V}$. Just after crossing the $1.0 \mathrm{~V}$, the device starts conducting with $0.0068 \mathrm{~mA}$ output current. During the start of current conduction, the recorded voltage was $1.2 \mathrm{~V}$. Therefore, the actuation voltage for the printed MEMS switch is $1.2 \mathrm{~V}$.

Figure 10 presents the plotted data for input voltage versus output current for connection type 1 . It is evident from the plot that it has three different regions, which are $0-1.2 \mathrm{~V}, 1.2-4.8 \mathrm{~V}$, and beyond $4.8 \mathrm{~V}$. The first region is $0-1.1 \mathrm{~V}$ where the switch is not turned on; the second is $1.2-4.8 \mathrm{~V}$ which is the active region for the switch; and finally, after $4.8 \mathrm{~V}$, the switch saturates.

After completely pulling down the clamp-clamp beam, we removed the ammeter between the cantilever and transmission line 2. RF signal from vector network analyzer is applied to transmission line 1 through the RF probe. The output from transmission line 2 is evaluated through the S21 parameter measurement using a vector network analyzer up to $13.5 \mathrm{GHz}$. The maximum insertion loss is about $5 \mathrm{~dB}$. The insertion loss could be further reduced by optimizing the conductivity of the transmission line.

To put the inkjet-printed MEMS switch in perspective with other microswitches, Table 6 summarized the experimental results of an electrostatically actuated MEMS switch.

\section{Conclusion}

This research work demonstrates a major milestone toward the fabrication of a 3D inkjet-printed flexible MEMS switch. The MEMS switch consists of three different layers with different sizes. A detailed analysis of each layer and 
TABLE 6: An upfront summary of the performance of the printed MEMS switch.

\begin{tabular}{lc}
\hline Actuation scheme & Electrostatic \\
Actuation voltage & $1.2 \mathrm{~V}$ \\
$R$ (clamp-clamp beam-transmission line), & $280 \sim 400 \Omega$ \\
connected by sacrificial layer & \\
$R$ (clamp-clamp beam-transmission line), & $2.5 \sim 3.0 \mathrm{M} \Omega$ \\
after removal of sacrificial layer & \\
$R$ (transmission line-transmission line), & $380 \sim 450 \Omega$ \\
connected by sacrificial layer & \\
$R$ (transmission line-transmission line), & $0.40 \sim 0.55 \mathrm{M} \Omega$ \\
after removal of sacrificial layer & $0.0001 \sim 0.2195 \mathrm{~mA}$ \\
Current capacity & $2195: 1$ \\
Current on-off ratio & $5 \mathrm{~dB}$ \\
RF insertion loss measured up to $13.5 \mathrm{GHz}$ & \\
\hline
\end{tabular}

characterization are also illustrated in this paper. The MEMS switch has a low actuation voltage of $1.2 \mathrm{~V}$, current capacity of $0.2195 \mathrm{~mA}$, a current on-off ratio of $2195: 1$, and an RF insertion loss of $5 \mathrm{~dB}$ up to $13.5 \mathrm{GHz}$. The performance of the MEMS switch could be further improved through the optimization of material selection and fabrication process. We believe that these results have paved the way for the development of next-generation high-performance, lightweight, mechanically flexible, and low-activation voltage RF MEMS switches for numerous phased-array antenna systems and other commercial and military communication applications.

\section{Conflicts of Interest}

The authors declare that they have no conflicts of interest.

\section{Acknowledgments}

This research was supported by NASA STTR Phase II under Contract no. NNX15CC34C and Northrop Grumman Grant no. 2206730. The authors would like to thank Jack Maceachern for his careful proofreading of this paper.

\section{References}

[1] M. Y. Chen, D. Pham, H. Subbaraman, L. Xuejun, and R. T. Chen, "Conformal ink-jet printed $C$-band phased-array antenna incorporating carbon nanotube field-effect transistor based reconfigurable true-time delay lines," IEEE Transactions on Microwave Theory and Techniques, vol. 60, no. 1, pp. 179184, 2012.

[2] J. Vaillancourt, H. Zhang, P. Vasinajindakaw et al., “All ink-jet printed carbon nanotube (CNT) thin-film transistor on a polyimade substrate with an ultra-high operating frequency of over 5 GHz," Applied Physics Letters, vol. 93, no. 24, article 243301, 2008.

[3] Z. Wang, A. F. Cook, X. Yang, Z. Liu, Y. Qingkai, and M. Y. Chen, "Graphene-based flexible field effect transistor with inkjet printed silver electrodes," Current Nanoscience, vol. 9, no. 5, pp. 635-637, 2013.
[4] M. A. Monne, E. Enuka, Z. Wang, and M. Y. Chen, "Inkjet printed graphene-based field-effect transistors on flexible substrate," in Proceedings of SPIE, vol. 10349 of Low-Dimensional Materials and Devices, pp. 1034905-1-1034905-6, San Diego, CA, USA, 2017.

[5] D. T. Pham, H. Subbaraman, M. Y. Chen, X. Xu, and R. T. Chen, "Self-aligned carbon nanotube thin-film transistors on flexible substrates with novel source-drain contact and multilayer metal interconnection," IEEE Transactions on Nanotechnology, vol. 11, no. 1, pp. 44-50, 2012.

[6] S. Gamerith, A. Klug, H. Scheiber, U. Scherf, E. Moderegger, and E. J. List, "Direct ink-jet printing of $\mathrm{Ag}-\mathrm{Cu}$ nanoparticle and Ag-precursor based electrodes for OFET applications," Advanced Functional Materials, vol. 17, no. 16, pp. 31113118, 2007.

[7] T. Dürkop, S. Getty, E. Cobas, and M. Fuhrer, "Extraordinary mobility in semiconducting carbon nanotubes," Nano Letters, vol. 4, no. 1, pp. 35-39, 2004.

[8] S. Khan and L. Lorenzelli, "Technologies for printing sensors and electronics over large flexible substrates: a review," IEEE Sensors Journal, vol. 15, no. 6, pp. 3164-3185, 2015.

[9] H. P. Le and Le Technologies Inc., "Progress and trends in ink-jet printing technology," Journal of Imaging Science and Technology, vol. 42, pp. 49-62, 1998.

[10] H. Wijshoff, "The dynamics of the piezo inkjet printhead operation," Physics Reports, vol. 491, no. 4-5, pp. 77-177, 2010.

[11] N. D. Sankir, Flexible Electronics: Materials and Device Fabrication, Virginia Polytechnic Institute and State University, Blacksburg, VA, USA, 2005.

[12] W. Van Hoeve, S. Gekle, J. H. Snoejer, M. Versluis, M. P. Brenner, and D. Lohse, "Breakup of diminutive Rayleigh jets," Physics of Fluids, vol. 22, no. 12, article 122003, 2010.

[13] V. R. Marinov, Y. A. Atanasov, A. Khan et al., "Direct-write vapor sensors on FR4 plastic substrates," IEEE Sensors Journal, vol. 7, no. 6, pp. 937-944, 2007.

[14] V. Mulloni, F. Giacomozzi, and B. Margesin, "Controlling stress and stress gradient during the release process in gold suspended micro-structures," Sensors and Actuators A: Physical, vol. 162, no. 1, pp. 93-99, 2010.

[15] D. Neculoiu, F. Giacomozzi, L. Bary et al., "Compact lumped elements micromachined band-pass filters with discrete switching for 1.8/5.2 GHz applications," in 2006 International Semiconductor Conference, pp. 107-110, Sinaia, Romania, 2006.

[16] X. Rottenberg, H. Jansen, P. Fiorini, W. De Raedt, and H. Tilmans, "Novel RF-MEMS capacitive switching structures," in 2002 32nd European Microwave Conference, pp. 1-4, Milan, Italy, 2002.

[17] H. S. Nalwa, Handbook of Nanostructured Materials and Nanotechnology, vol. 5, Academic Press, San Diego, CA, USA, 1999.

[18] S. Chung, M. A. Karim, H. J. Kwon, W. Scheideler, and V. Subramanian, "A high-speed inkjet-printed microelectromechanical relay with a mechanically enhanced doubleclamped channel-beam," Journal of Microelectromechanical Systems, vol. 26, no. 1, pp. 95-101, 2016.

[19] J. Mort and G. Pfister, Electronic Properties of Polymers, John Wiley \& Sons, Hoboken, NJ, USA, 1982.

[20] Dupont, "Dupont ${ }^{\mathrm{TM}}$ Kapton $^{\circledR}$ HN Polyimide Film," 2016, http://www.dupont.com/content/dam/dupont/products-and- 
services/membranes-and-films/polyimde-films/documents/ DEC-Kapton-HN-datasheet.pdf.

[21] Novacentrix, "Metalon ${ }^{\circledR}$ conductive inks for printed electronics," https:/www.novacentrix.com/sites/default/files/pdf/ Metalon\%20JS-B40G.PDF.

[22] S. Aldrich, "Jetting instructions for Orgacon ${ }^{\mathrm{TM}}$ IJ-1005," March 2012, https://www.sigmaaldrich.com/content/dam/ sigma-aldrich/docs/Sigma/Product_Information_Sheet/1/ 739316pis.pdf. 


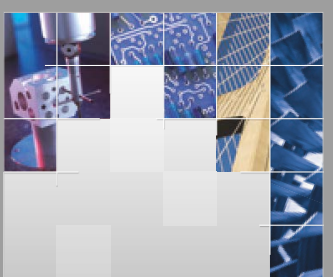

\section{Enfincering}
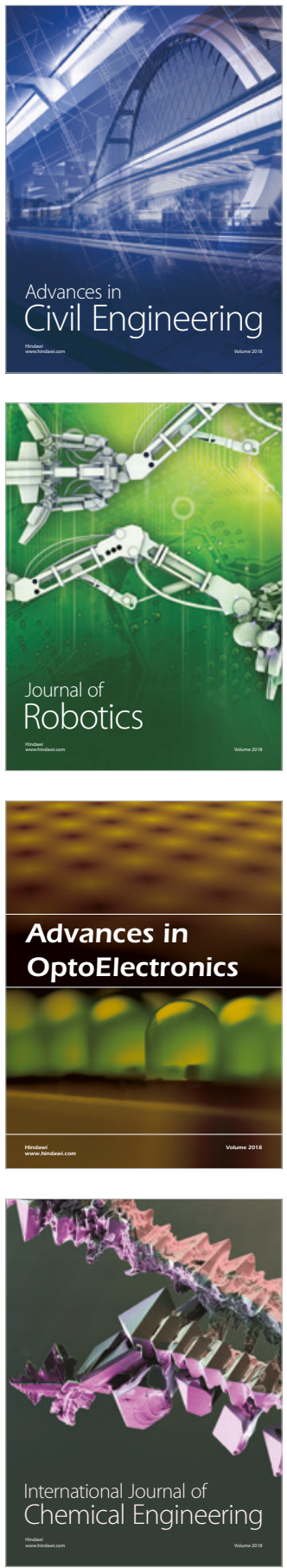

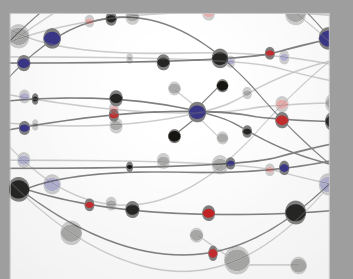

\section{Rotating \\ Machinery}

The Scientific World Journal

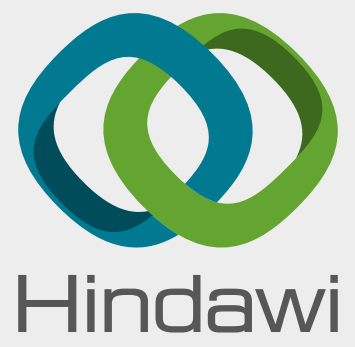

Submit your manuscripts at

www.hindawi.com
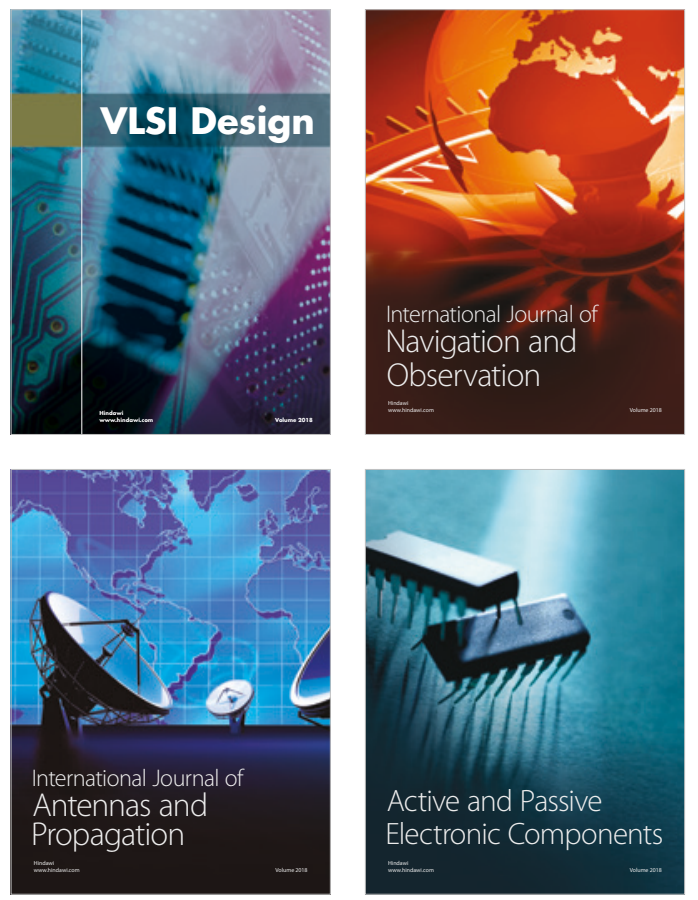
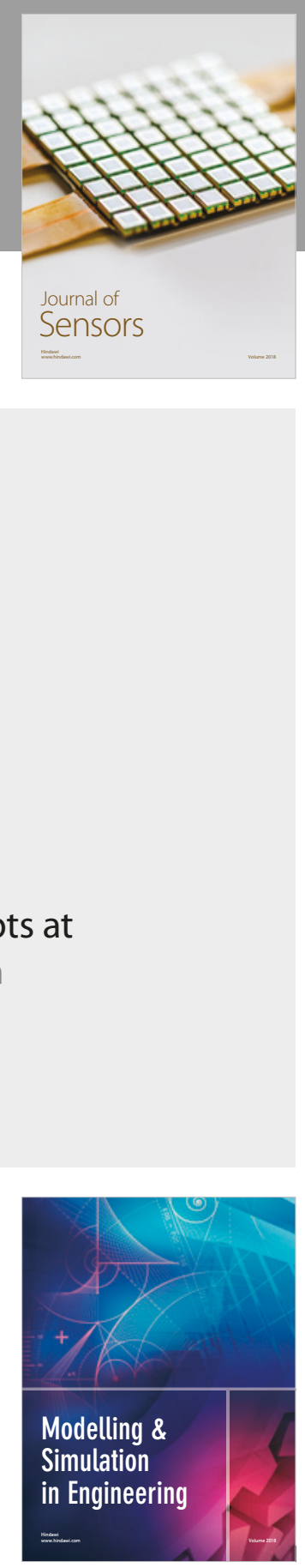

\section{Advances \\ Multimedia}
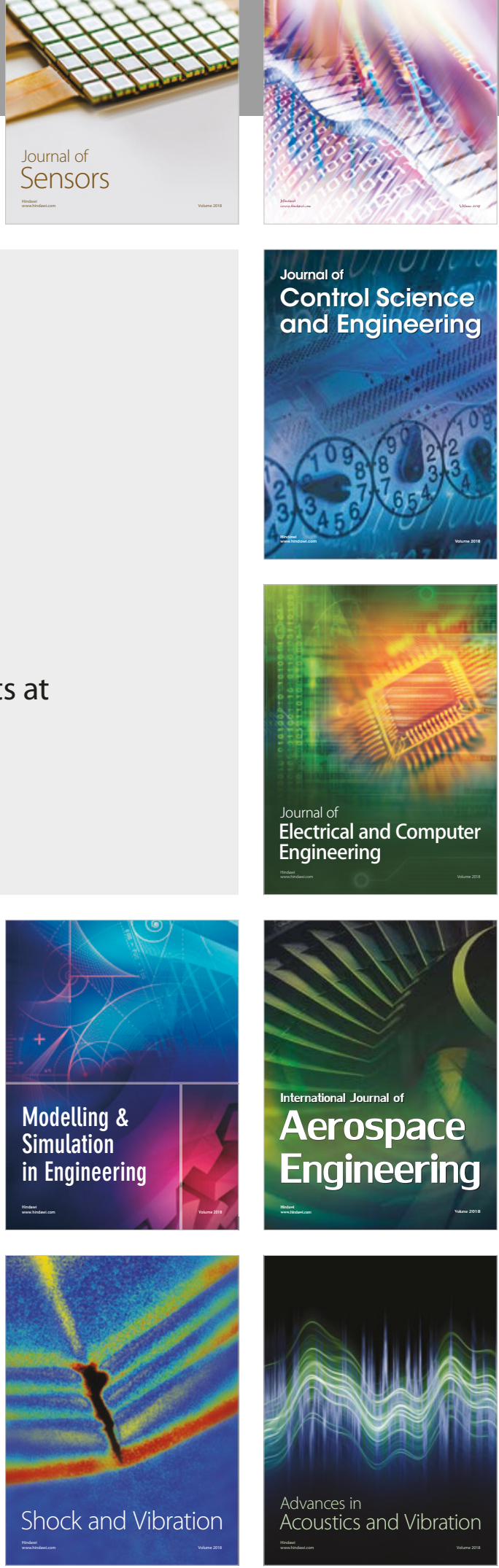